\title{
SINTOMAS EXISTENCIAIS VERSUS SINTOMAS PSICOPATOLÓGICOS: UM PROBLEMA DE ROTULAGEM PSIQUIÁTRICA - INQUÉRITO SOBRE A VIVÊNCIA DE PROFISSIONAIS DA SAÚDE MENTAL
}

\author{
Edna Paciência Vietta* \\ Sônia Maria Villela Bueno**
}

\begin{abstract}
RESUMO. No presente trabalho objetivou-se verificar sintomas emocionais que os docentes de enfermagem consideram normais e anormais; como se percebem dentro deste referencial e como evidenciam o tratamento psiquiátrico. Para tal, elaborou-se um questionário com base numa lista de sintomas, com questões pertinentes ao assunto. Os resultados evidenciaram que a população estudada considerou como sintomas normais vivenciados: ansiedade, desânimo, depressão, agressividade, angústia, sentimento de culpa, inferioridade e vontade de agredir; e como não vivenciados, anormais: delírio, alucinação, idéias obsessivas e vontade de matar.
\end{abstract}

\begin{abstract}
The objective of the present study was to determine the emotional symptoms that nursing teachers consider normal and abnormal, how they perceive themselves within this frame of reference and how the look upon psychiatric treatment. Who were asked to answer a questionnaire based on a list of symptoms. The results showed that the population studied considered the following symptoms to be part of normal day-to-day living: ansciety, descouragement, depression, aggressiveness, anguish, guiet feelings, inferiority and the wihs to aggrest others; and to be abnormal symptons, not part of daily life, the following ones: delirium, hallucinations, obsessive ideas and the wish to kill.
\end{abstract}

\section{INTRODUC̣ÃO}

A absoluta maioria da humanidade, tem problemas emocionais de maior ou menor importância. Esses problemas afetam a existência dos indivíduos, desencadeando sintomas físicos e emocionais os mais diversos possíveis. A vida competitiva da sociedade de consumo de nossos dias, insegurança no trabalho e nas ruas, também contribuam fortemente com seu ônus para a higidez mental. Em conseqüência, nâo é de se admirar que haja uma elevada incidência de pessoas com insônia, incapacidade para concentrar-se e de abstrair-se, com sintomas que provocam distúrbios digestivos, depressão, angústia, dores de cabeça, cansaço excessivo, perda da autoconfiança e da capacidade de iniciativa, elevada irritabilidade emocional e muitos outros sintomas existenciais. Há, por outro lado, uma tendência generalizada de se identificar tais "sintomas" como indícios de doença mental chegando, muitas vezes, ao cúmulo de enquadrá-los na clássica nosologia psiquiátrica engajando o seu portador na classificação de neurótico ou psicótico, quando não em quadros mais específicos como histéricos, hipocondríacos, deprimidos, obsessivos, fóbicos, esquisof rênicos, paranóicos e assim por diante.

Assim sendo, tem-se observado que, desde os tempos mais remotos, o ser humano vem sendo classificado de acordo com valores, crenças, sintomas e comportamentos diversos. A esse respeito SZASZ (1979), lembrando que o homem é o único animal que classifica, comenta que vivemos numa era científica e na qual depositamos fé ilimitada nos métodos das Ciências Físicas, levando seu pensamento mais longe, assevera que, apoiado nesta certeza, o homem extrapola e afir-

\footnotetext{
* Prof. Assistente Dra. do Departamento de Enfermagem Psiquiátrica e Ciências Humanas da EERP-USP

** Prof. Assistente do Departamento de Enfermagem Psiquiátrica e Ciências Humanas da EERP-USP (Pedagogia).
} 
ma que, se podemos classificar o comportamento de estrelas e animais, porque não o comportamento dos homens? A esta pergunta é o próprio autor quem responde não ser admissível tal relação, na medida em que a lógica da Ciência Física é patentemente falsa diante da Ciência do Comportamento: negligencia as diferenças entre as pessoas e coisas e os ef eitos da linguagem em cada uma delas.

A linguagem da Física nos ajuda e compreender e a manipular objetos físicos. Se a concebermos para a Psiquiatria ou Psicologia, sua linguagem especial deverá servir a um propósito semelhante; ajudar-nos a compreender e controlar pessoas. Mas, seria moralmente legítimo controlar ou manipular seres humanos?

A verdade-é que enquadrar pessoas em determinadas classes as afetam profundamente, fato este não observado no caso dos animais e coisas. Por exemplo, o rótulo de esquisof rênico é algo que estigmatiza a pessoa. 0 rótulo de "quiróptero" ao morcego ou o de "granito" a uma rocha, em nada os afeta. Em outras palavras, em psiquiatria e em questões humanas, $o$ ato de classificação é um evento basicamente significativo. Uma vez imprimida a rotulação, as outras particularidades da pessoa, sobretudo as positivas, deixam de ser consideradas e ela é degradada e desumanizada, reduzido mesmo a uma coisa (JACCARD, 1981). Para BARRETO (1978), os nomes usados para classificar as doenças mentais, são puramente descritivos e não abrangem, de modo algum explicações etiológicas, constituem apenas rótulos.

A classificação é um ato humano e social. À classificação de indivíduos ou grupos acarreta a participação de pelo menos três tipos distintos de pessoas: aquele que classifica, o classificado e um público a quem cabe aceitar ou rejeitar uma determinada classificação. Um indivíduo pode classificar a si mesmo e aos outros e, por sua vez, pode ser classificado por outros. Em cada caso, a categorização proposta por aquele que classifica pode ser aceita ou rejeitada pelos outros. Para que uma classificação de si ou de outros seja aceita, é necessário, em geral, uma medida de poder sobre os outros; este poder pode ser intelectual (científico) ou político (coercitivo).

Como classificador, o homem também ataca o objeto de seu interesse classificatório, não para devorá-lo mas para controlá-lo. A Ciência pode ser vista como a soma total do esforço humano para compreender a natureza e desse modo obter uma medida do controle sobre ela.

Na verdade, a classificação psiquiátrica leva os indivíduos rotulados à segregação social. A partir do momento em que o paciente é classificado numa nosografia, ele deixa sua situação de sujeito a quem se fala para a e de objeto do qual se fala e do qual se dispõe.

Na relativamente curta história da psiquiatria, de trezentos anos, a condição agora chamada de doença mental foi rotulada e re-rotulada como loucura, insa- nidade, esquisof renia, neurose, psiconeurose, psicose, descontrole do ego, desordem emocional e assim por diante.

Na procura de alívio para a carga de suas responsabilidades morais, o homem moderno mistifica e torna técnicos seus problemas de vida.

A conquista da existência humana ou do processo vital pelas profissões ligadas à saúde mental começou com a identificação e classificação das chamadas doenças mentais e culminou em nossos dias, com a afirmação de qeu tudo na vida é um problema psiquiátrico, que a ciência do comportamento deve resolver. A partir do início do século, especialmente depois de cada uma das duas grandes guerras mundiais, o ritmo da conquista psiquiátrica cresceu rapidamente. 0 resultado é que hoje todas as dificuldades e problemas da vida são considerados doenças psiquiátricas e todos (exceto aqueles que diagnosticam) são considerados doentes mentais. Esse processo de tornar médicos e psiquiátricos e, em geral, técnicos os problemas pessoais, sociais e políticos tem sido uma característica dominante na era moderna e burocrática.

Essa tendência classificatória tem sido de tal forma difundida, que ao simples sinal ou sintoma da presença de um problema, as pessoas que se angustiam, supondo estarem com transtornos mentais graves. Sintomas como apatia, ansiedade, depressão, insônia, tão comuns na sociedade capitalista, onde as preocupações, a busca incessante de "status", a competição, a supervalorização do poder aquisitivo, os problemas financeiros, refletem situaçẽos existenciais, as pessoas procuram nas drogas, soluções para o seu alívio. Até mesmo os profissionais da área de saúde, têm sido incoerentes e contraditórios ao classificarem de doentes mentais, indivíduos com sintomas existenciais (SZASZ, 1979).

A classificação pressupõe um diagnóstico diferencial entre o que é não patológico e o que é patológico. 0 que é doença e o que é saúde? 0 que é normal e o que é anormal? Quem é o doente mental?

O fato de um desvio em particular, ser classificado como doença, numa dada sociedade, depende basicamente de ser percebido pelas pessoas como um desvio de saúde e, como tal, de pertencer ao domínio dos profissionais especializados na cura, assim como depende da aceitação do desvio, por parte destes, como sendo de sua alçada. Por outro lado, a classificação dos desvios na sociedade, é um processo contínuo, sendo muitos tipos reclassificados de tempos em tempos, de acordo com as alterações nos conceitos acerca de sua natureza.

A principal controvérsia contemporânea em torno da questão de quem deve ser considerado mentalmente enfermo, foi iniciada por alguns psiquiatras e cientistas sociais, que argumentaram que a tendência a encarar um número cada vez maior de desvios como 
doença mental já estava indo longe demais (MILES, 1982).

Nossa preocupação atual tem sido a de contribuir para que tal tendência não se difunda ainda mais, agravando o problema do rótulo em psiquiatria.

Neste intuito, entendemos ser de fundamental importãncia pesquisar o que os profissionais da saúde entendem como sintomas patológicos e sintomas existenciais, pois que, deste entendimento, pensamos ser possível identificar o conceito de saúde e doença, os quais utilizam para suas avaliações pessoais que, com certe$\mathrm{za}$, refletem em seu proceder, como pessoa e como profissional, supondo que ele utilize os mesmos critérios para classificar outros.

\section{OBJETIVOS}

0 presente trabalho objetiva investigar, como os conceitos de normalidade e anormalidade interferem na atuação dos docentes em enfermagem. Isto implica em:

\subsection{Identificar mais sintomas os docentes de enf erma- gem consideram normais ou anormais.}

\subsection{Verificar como o docente de enfermagem se per-} cebe dentro do referencial normal e anormal.

\section{METODOLOGIA}

\subsection{População}

Trabalhou-se com docentes de enfermagem de diferentes áreas, de cinco Escolas de Enfermagem de cidades no interior de São Paulo: Escola de Enfermagem de Ribeirão Preto-USP; FEO de Saúde Barão de Mauá . Ribeiro Preto; Escola de Enfermagem F.E.F.O.F. Fernandópolis; Departamento de Enfermagem da FCMUNICAMP - Campinas; Departamento de Enfermagem F.A.M.E.M.A. - Marilia. Esta população teve como critério de seleção, a representação de cada um dos alunos, matriculados na disciplina "Enfermagem Psiquiátrica dirigida a pacientes internados" do Curso de Pós-Graduação - Área Enfermagem Psiquiátrica do Departamento de Enfermagem Psiquiátrica e Ciências Humanas da Escola de Enfermagem de Ribeirão Preto (E.E.R.P. - USP).

\subsection{Amostra:}

Seis (6) docentes de cada uma das instituições selecionadas aos quais foram incluídos seis (6) alunos do referido curso, totalizando 36 sujeitos.

\subsection{Instrumentos:}

0 questionário constou fundamentalmente de duas partes: dados de identificação e questões mistas (aber- tas e fechadas) relacionadas ao tema proposto, elaboradas a partir de uma listagem de sintomas (21 itens) composto por 13 questões, sendo quatro (4) relativas ao conceito de normalidade e anormalidades e seis (6) sobre tratamento psiquiátrico; duas (2) sobre critérios de conduta e duas (2) sobre vivências terapêuticas.

Dado a riqueza de dados e da necessidade de uma análise psicodinâmica mais profunda, tendo em vista a precariedade de tempo, analisaremos os dados correspondentes apenas às 9 (nove) primeiras questões.

\subsection{Procedimentos:}

0 questionário foi aplicado inicialmente aos alunos de pós-graduação cujos resultados serviram para aferir o instrumento, servinto também como plano piloto. Esta etapa serviu para motivar o grupo o qual decidiu colaborar na investigação, assumindo juntamente com as coordenadoras do curso a responsabilidade pela aplicação do instrumento como execução de tarefa para avaliação didática.

Os questionários foram distribuídos entre os docentes das referidas escolas, entregues ao acaso, seguidos de orientação e esclarecimentos oral, individual, sobre os objetivos da pesquisa, ficando o entrevistador a disposição dos entrevistados para quaisquer dúvidas. Estabeleceu-se um período de tempo flexível baseado no tempo em que os entrevistadores levaram em média para preenchimento do referido questionário (trinta minutos).

\subsection{Definição operacional}

No presente trabalho considera-se cada um dos sintomas listados no instrumento como situados numa escala representada por um continuum delimitados pelos extremos: "normalidade" - "anormalidade" e cuja localização do sintoma, nesta escala, dependerá da intensidade, freqũência, situação e momento em que está sendo vivenciado.

\section{RESULTADOS E DISCUSSÃO}

Os resultados apresentados na Tabela 1 revelam que a grande maioria dos sujeitos da amostra estudada já vivenciou a maioria dos sintomas da lista apresentada. Alguns deles indicados com maior freqüência como ansiedade, desânimo, depressão, sentimentos de culpa, angústia, sentimento de inferioridade, agressividade, com predominância da ansiedade e do desânimo com $100 \%$ de indicação. Estes dois sintomas são referidos por MAY (1977), como integrantes do círculo vicioso da condição humana: neste processo "impotência diante do ser resulta de uma ameaça ou de perda, o que vem a converter-se em ansiedades; esta resulta em regressão e apatia, daí a hostilidade, e esta numa alienação do homem em relação ao homem: a desper- 
sonalização, com todos os sintomas característicos de nossa cultura com sentimentos de inferioridade, culpa e depressão". Se considerarmos ansiedades como sinônimo de angústia, se incluirmos o desânimo com a depressão, diríamos que estes sintomas foram vivenciados pela totalidade da população, o que corresponde a afirmação de que tais sintomas são inerentes ao homem contemporâneo no enfoque existencialista.

Outros sintomas bastante indicados foram insônia (28\%), agitaçâo (27\%), apatia (26\%), vontade de agredir (26\%) e o desespero (22\%). Esses sintomas se relacionados com os anteriores, também terão suas porcentagens alteradas. Por exemplo, a agitação e o desespero com a depressão ou agressividade, a insônia com a ansiedade e depressão e o sentimento de culpa ou a vontade de agredir, com a mesma agressividade ou, ainda, sentimento de inferioridade com a ansiedade e depressão teríamos certamente que alterarmos as porcentagens. Na realidade, psicodinamicamente, todos esses sintomas são extremamente interdependentes e interrelacionados.

Os sintomas vivenciados pela amostra foram considerados pelos sujeitos como sintomas normais, quando vivenciados com intensidade considerada. Estes fo- ram, segundo Tabela 2, depressão, sentimentos de culpa, sentimento de inferioridade, desânimo, apatia, agressividade, angústia e vontade de agredir.

A ansiedade, embora vivenciada com bastante intensidade por alguns docentes, $50 \%$ a vivenciou em grau intenso, $28 \%$ em grau moderado e apenas $22 \%$ em grau leve, ainda foi considerado um sintoma normal(Tabelas 2 e 3 ).

Atacando especificamente o problema da ansiedade, Kierkegaard observou que escapamos à ansiedade à medida que nos tornamos livres como indivíduos $\mathrm{e}$, ao mesmo tempo que realizamos a comunidade com os nossos semelhantes. A ansiedade, como ele expressou epigramaticamente, é "a vertigem da liberdade". Para KIERKEGAARD citado por MAY $(1977,1980)$, liberdade significa uma expansão da autoconsciência e da capacidade de atuar responsavelmente como um Eu. Significa uma capacidade crescente de fazer face às nossas possibilidades, tanto no desenvolvimento individual como no aprofundamento das relações com os nossos semelhantes, juntamente com uma concretização dessas possibilidades. Essa realização das possibilidades é um aventurar contínuo em novas áreas.

PORTMANN salienta que KIERKEGAARD conce-

TABELA 1 - Distribuição numérica e percentual da opinião da população referente à vivência ou não dos sintomas emocionais.

\begin{tabular}{|c|c|c|c|c|c|c|c|c|c|c|}
\hline \multirow{3}{*}{ SINTOMAS EMOCIONAIS } & \multicolumn{8}{|c|}{ RESPOSTAS } & \multirow{2}{*}{\multicolumn{2}{|c|}{ TOTAL }} \\
\hline & \multicolumn{2}{|c|}{ VIVENCIADOS } & \multicolumn{2}{|c|}{ NÃO VIVENCIADOS } & \multicolumn{2}{|c|}{ BRANCO } & \multicolumn{2}{|c|}{ NULO } & & \\
\hline & No & $\%$ & No & $\%$ & No & $\%$ & No & $\%$ & No & $\%$ \\
\hline 1. ansiedade & 36 & 100 & - & - & - & - & - & - & 36 & 100 \\
\hline 2. angústia & 33 & 92 & 2 & 5 & 1 & 3 & - & - & 36 & 100 \\
\hline 3. depressão & 35 & 97 & 1 & 3 & - & - & - & - & 36 & 100 \\
\hline 4. fobia & 13 & 36 & 23 & 64 & - & - & - & - & 36 & 100 \\
\hline 5. idéias obsessivas & 9 & 25 & 24 & 75 & - & - & - & - & 36 & 100 \\
\hline 6. agitação & 27 & 75 & 9 & 25 & - & - & - & - & 36 & 100 \\
\hline 7. agressividade & 30 & 83 & 6 & 17 & - & - & - & - & 36 & 100 \\
\hline 8. apatia & 26 & 72 & 10 & 28 & - & - & - & - & 36 & 100 \\
\hline 9. insônia & 28 & 78 & 8 & 22 & - & - & - & - & 36 & 100 \\
\hline 10. alucinação & 1 & 3 & 35 & 97 & 1 & 3 & - & - & 36 & 100 \\
\hline 12. sentimento de culpa & 35 & 97 & 1 & 3 & - & - & - & - & 36 & 100 \\
\hline 13. sentimento de inferioridade & 34 & 94 & 2 & 5 & - & - & - & - & 36 & 100 \\
\hline 14. sentimento de perseguição & 11 & 30 & 25 & 69 & - & - & - & - & 36 & 100 \\
\hline 15. sensação de pãnico & 14 & 39 & 20 & 55 & 2 & 5 & - & - & 36 & 100 \\
\hline 16. desãnimo & 36 & 100 & - & - & - & - & - & - & 36 & 100 \\
\hline 17. vontade de morrer & 18 & 50 & 18 & 50 & - & - & - & - & 36 & 100 \\
\hline 18. desespero & 22 & 61 & 14 & 39 & - & - & - & - & 36 & 100 \\
\hline 19. vontade de agredir & 26 & 72 & 10 & 28 & - & - & - & - & 36 & 100 \\
\hline 20. vontade de matar & 7 & 19 & 28 & 78 & 1 & 1 & - & - & 36 & 100 \\
\hline
\end{tabular}

NOTA: apareceu na alternativa outros: rejeição ( \pm vivenciado); solidão (1 vivenciado) e euforia (1 vivenciado). 
beu essa ansiedade como "normal", "não neurótica". O seu conceito era um precursor do que OTTO RANCK descreveria, mais tarde, como a ansiedade inerente à individualização e o que Kurt Goldstein descreveu como a ansiedade normal quando o indivíduo se defronta com os inevitáveis choques do crescimento e da experiência.

Não queremos com esta análise negar a existência da ansiedade neurótica. Esta estará determinada entre inúmeros fatores pela intensidade em que ela aparecer e o nível em que o indivíduo a suportar. Os sintomas considerados como normais na amostra são classificados como sintomas neuróticos pela classificação nosológica e portanto mais admissíveis e toleráveis pelos indivíduos sendo talvez mais fáceis de serem admitidos.

Os sintomas não vivenciados (Tabela 1) indicados pela amostra foram: alucinação, delírio, vontade de matar, idéias obsessivas, sentimento de perseguição, fobias, sensação de pãnico, vontade de morrer que coincidem com os sintomas indicados como anormais (Tabela 2) por um número razoável da amostra. A alucinação e o delírio foram sintomas vivenciados por apenas $3 \%$ e $5 \%$ respectivamente. No entanto deixaram de opinar quanto a normalidade/anormalidade dos sintomas (Tabela 2); fobia 53\%; apatia e idéias obsessivas $44 \%$; delírio $42 \%$; vontade de matar, vontade de agredir, desespero, agressividade $30 \%$; sentimento de perseguição, sensação de pânico $36 \%$, e vontade de morrer, sentimento de inferioridade, alucinação, insônia $33 \%$, resultados para os quais não temos elementos para análise. Podemos no entanto inferir como resistências ou dificuldades de compreensão. Sintomas neuróticos pela classificação internacional como a fobia e idéias obsessivas; sintomas enquadrados como psicóticos na referida nosologia psiquiátrica como delírio, alucinação, e sentimento de perseguição ou são logo identificados como anormais ou podem ser dificilmente admitidos como vivenciados. Outra possibilidade é a de que o indivíduo possa não ter consciência de sintomas como alucinação e delírio. Outros sintomas que envolvem agressão ou auto agressão parecem ser pouco aceitos na nossa sociedade tanto que geralmente são fortemente reprimidos (vontade de matar e vontade de morrer) e, portanto, também difíceis de serem admitidos.

Do total da amostra, conforme a Tabela 4, 52,7\% dos sujeitos estudados consideram-se equilibrados, portanto significando a metade da amostra; $44,5 \%$ consideram-se mais ou menos equilibrados, apenas $2,8 \%$ consideram-se muito equilibrados, confirmando, assim, a indicação de vivências de sintomas admitidos pela maioria, conforme a Tabela 3, como sintomas normais quando vivenciados em grau leve ou moderado ou

TABELA 2 - Distribuição numérica e percentual da opinião da população referente à questão "Qual desses sintomas considera normais e anormais".

\begin{tabular}{|c|c|c|c|c|c|c|c|c|}
\hline \multirow{3}{*}{ SINTOMAS EMOCIONAIS } & \multicolumn{8}{|c|}{ RESPOSTAS } \\
\hline & \multicolumn{2}{|c|}{ NORMAL } & \multicolumn{2}{|c|}{ ANORMAL } & \multicolumn{2}{|c|}{ EM BRANCO } & \multicolumn{2}{|c|}{ TOTAL } \\
\hline & No & $\%$ & No & $\%$ & No & $\%$ & No & $\%$ \\
\hline 1. ansiedade & 30 & 83 & - & - & 6 & 17 & 36 & 100 \\
\hline 2. angústia & 24 & 67 & 5 & 14 & 7 & 19 & 36 & 100 \\
\hline 3. depressão & 22 & 61 & 4 & 11 & 10 & 28 & 36 & 100 \\
\hline 4. fobia & 6 & 17 & 11 & 30 & 19 & 53 & 36 & 100 \\
\hline 5. idéias obsessivas & 4 & 11 & 16 & 44 & 16 & 44 & 36 & 100 \\
\hline 6. agitacão & 22 & 61 & 3 & 8 & 11 & 30 & 36 & 100 \\
\hline 7. agressividade & 15 & 42 & 7 & 19 & 14 & 39 & 36 & 100 \\
\hline 8. apatia & 16 & 44 & 4 & 11 & 16 & 44 & 36 & 100 \\
\hline 9. insônia & 18 & 50 & 6 & 17 & 12 & 33 & 36 & 100 \\
\hline 10. alucinacão & 4 & 11 & 20 & 55 & 12 & 33 & 36 & 100 \\
\hline 11. delírio & 3 & 8 & 18 & 50 & 15 & 42 & 36 & 100 \\
\hline 12. sentimento de culpa & 20 & 55 & 6 & 17 & 10 & 28 & 36 & 100 \\
\hline 13. sentimento de inferioridade & 21 & 58 & 3 & 8 & 12 & 33 & 36 & 100 \\
\hline 14. sentimento de perseguição & 10 & 28 & 13 & 36 & 13 & 36 & 36 & 100 \\
\hline 15. sensacão de pãnico & 13 & 36 & 10 & 28 & 13 & 36 & 36 & 100 \\
\hline 16. desãnimo & 25 & 69 & 2 & 5 & 9 & 25 & 36 & 100 \\
\hline 17. vontade de morrer & 11 & 30 & 13 & 36 & 12 & 33 & 36 & 100 \\
\hline 18. desespero & 18 & 50 & 4 & 11 & 14 & 39 & 36 & 100 \\
\hline 19. vontade de agredir & 17 & 47 & 5 & 14 & 14 & 39 & 36 & 100 \\
\hline 20 . vontade de matar & 8 & 22 & 14 & 39 & 14 & 39 & 36 & 100 \\
\hline
\end{tabular}

NOTA: em outros, aparecem rejeição, solidão e euforia como normais. 
TABELA 3 - Distribuição numérica e percentual da opinião da população referente a questão "Em que intensidade você os vivenciou".

\begin{tabular}{|c|c|c|c|c|c|c|c|c|c|c|}
\hline \multirow{3}{*}{ SINTOMAS EMOCIONAIS } & \multicolumn{8}{|c|}{ RESPOSTAS } & & \\
\hline & \multicolumn{2}{|c|}{$\mathbf{X}$} & \multicolumn{2}{|c|}{$\mathbf{X X}$} & \multicolumn{2}{|c|}{$\mathbf{X X X}$} & \multicolumn{2}{|c|}{ EM BRANCO } & \multicolumn{2}{|c|}{ TOTAL } \\
\hline & N. ${ }^{\circ}$ & $\%$ & N. ${ }^{\circ}$ & $\%$ & N.o & $\%$ & N. ${ }^{\circ}$ & $\%$ & $\mathbf{N} .^{\mathbf{o}}$ & $\%$ \\
\hline 1. ansiedade & 8 & 22 & 10 & 28 & 18 & 50 & - & - & 36 & 100 \\
\hline 2. angústia & 13 & 36 & 17 & 47 & 4 & 11 & 2 & 5 & 36 & 100 \\
\hline 3. depressão & 20 & 55 & 10 & 28 & 5 & 14 & 1 & 3 & 36 & 100 \\
\hline 4. fobia & 9 & 25 & 1 & 3 & 2 & 5 & 24 & 67 & 36 & 100 \\
\hline 5. idéias obsessivas & 5 & 14 & 4 & 11 & - & - & 27 & 75 & 36 & 100 \\
\hline 6. agitação & 11 & 30 & 9 & 25 & 6 & 17 & 10 & 28 & 36 & 100 \\
\hline 7. agressividade & 13 & 36 & 12 & 33 & 3 & 8 & 8 & 22 & 36 & 100 \\
\hline 8. apatia & 14 & 39 & 10 & 28 & - & - & 12 & 33 & 36 & 100 \\
\hline 9. insônia & 16 & 44 & 6 & 17 & 4 & 11 & 10 & 28 & 36 & 100 \\
\hline 10. alucinação & & - & - & - & - & - & 36 & 100 & 36 & 100 \\
\hline 11. delírio & 1 & 3 & - & - & & - & 35 & 97 & 36 & 100 \\
\hline 12. sentimento de culpa & 19 & 53 & 13 & 36 & 1 & 3 & 3 & 8 & 36 & 100 \\
\hline 13. sentimento de inferioridade & 19 & 53 & 10 & 28 & 4 & 11 & 3 & 8 & 36 & 100 \\
\hline 14. sentimento de perseguição & 9 & 25 & 2 & 5 & & - & 25 & 69 & 36 & 100 \\
\hline 15. sensação de pãnico ${ }^{\circ}$ & 9 & 25 & 2 & 5 & 2 & 5 & 23 & 64 & 36 & 100 \\
\hline 16. desãnimo & 19 & 53 & 11 & 30 & 6 & 17 & - & - & 36 & 100 \\
\hline 17. vontade de morrer & 9 & 25 & 4 & 11 & 1 & 3 & 22 & 61 & 36 & 100 \\
\hline 18. desespero & 7 & 19 & 5 & 14 & 1 & 3 & 23 & 64 & 36 & 100 \\
\hline 19. vontade agredir & 12 & 33 & 11 & 30 & 4 & 11 & 9 & 25 & 36 & 100 \\
\hline 20. vontade de matar & 6 & 17 & 3 & 8 & 1 & 3 & 26 & 72 & 36 & 100 \\
\hline
\end{tabular}

NOTA: em outros apareceu: 1 solidão (X); 1 euforia (XX); 2 rejeição (XXX).

As intensidades, estabeleceu-se as seguintes graduações:

$\mathrm{X}$ (leve), XX (moderado), XXX (intenso).

TABELA 4 - Distribuição numérica e percentual de resposta da população quanto à 4? questão: "Você se considera um indivíduo: equilibrado; mais ou menos equilibrado ou muito equilibrado?

\begin{tabular}{lrr}
\hline \multirow{2}{*}{ RESPOSTAS } & \multicolumn{2}{c}{ FREQÜÊNCIA } \\
\cline { 2 - 3 } & N? & \multicolumn{1}{c}{$\%$} \\
\hline - Equilibrado & 19 & 52,7 \\
- Mais ou menos equilibrado & 16 & 44,5 \\
- Muito equilibrado & 1 & 2,8 \\
\hline TOTAL GERAL & 36 & 100,0 \\
\hline
\end{tabular}

quando considerado normal mesmo em grande intensidade como no caso do sintoma de ansiedade. Coincide ainda com a indicação de sintomas patológicos ou anormais, não vivenciadas pela amostra ou não referido pelo percentual de respostas em branco que, haja visto, teve elevada freqüência nos sintomas fobias, idéias obsessivas, alucinações, delírio, sentimento de perseguição. Sabe-se, no entanto, que nem sempre es-
TABELA 5A - Distribuição numérica e percentual da resposta da população quanto à $5^{a}$ ? questão: Você fez ou está fazendo algum tratamento psicoterápico?"

\begin{tabular}{|c|c|c|c|}
\hline & \multirow{2}{*}{ RESPOSTAS } & \multicolumn{2}{|c|}{ FREQÜÊNCIA } \\
\hline & & No & $\%$ \\
\hline - Sim & & 9 & 25 \\
\hline - Não & & 27 & 75 \\
\hline TOTAL & & 36 & 100 \\
\hline
\end{tabular}

tes sintomas são indícios de anormalidade. Por exemplo, uma pessoa normal pode ter alucinações sob condições excepcionais como na hipnose, excitação intensa, ingestão de drogas, redução acentuada dos estímulos sensoriais e até numa simples febre. A imaginação, uma experiência com a característica da percepção sensorial (visão, sons, gosto, tato e assim por diante) pode ser evocada por condições tóxicas, tumores e substâncias químicas. A pessoa não consegue distinguir esta experiência das que foram evocadas por processos sen- 
soriais naturais, mesmo que a experiência se apresente bastante bizarra. A percepção é experimentada como real. Daí não poder ser identificada como anormal. Além disso as alucinações podem ser evocadas por uma severa tensão emocional e física.

A Tabela 5A evidencia que a grande maioria dos sujeitos da amostra (75\%) informa não estar sendo submetido a nenhum tipo de tratamento psicoterápico, porém $59,3 \%$ já pensou em se submeter a um tratamento desta natureza. Coerentes portanto com a afirmação de que a maioria $52,7 \%$ se consideram equilibrada e $44,5 \%$ mais ou menos equilibrados. No entanto, conforme resultados apresentados na Tabela $5 \mathrm{~B}, 59,3 \%$, já pensou em se submeter a tratamento psicoterápico.

TABELA 5B - Distribuição numérica e percentual da resposta da população quanto à 5 a questão: "Se não faz tratamento psicoterápico, já pensou em submeter a esse tratamento?"

\begin{tabular}{lcc}
\hline \multirow{2}{*}{ RESPOSTAS } & \multicolumn{2}{c}{ FREQÜÊNCIA } \\
\cline { 2 - 3 } & No & $\%$ \\
\hline • Sim & 16 & 59,3 \\
• Não & 11 & 40,7 \\
\hline TOTAL & 27 & 100,0 \\
\hline
\end{tabular}

* 0 total não corresponde ao total 36 porque esta questão complementa a tabela anterior.

Quanto a utilização de drogas psicotrópicas, (Tabela 6) $88 \%$ dos sujeitos informam não utilizar nenhum tipo de medicação desta natureza, enquanto uma minoria $11,1 \%$ informa fazer uso freqüente das seguintes medicações:

NOAN, AD, LEXIL, LORIUM e EQUILID, medicamentos estes classificados como tranqüilizantes menores ou ansiolíticos. 0 que nos leva a pensar no grau de tensão ou ansiedade a ser tolerado varia de indivíduo para indivíduo.

TABELA 6 - Distribuição numérica e percentual da resposta da produção da população quanto à 6 . questão: "Você fez ou está fazendo uso de alguma droga psicoterápica: ansiolítico, tranqüilizante ou anti-depressivo?"

\begin{tabular}{|c|c|c|}
\hline \multirow{2}{*}{ RESPOSTAS } & \multicolumn{2}{|c|}{ FREQÜÊNCIA } \\
\hline & No & $\%$ \\
\hline $\begin{array}{l}\text { - Sim } \\
\text { - Não }\end{array}$ & $\begin{array}{r}4 \\
32\end{array}$ & $\begin{array}{l}11,2 \\
88,9\end{array}$ \\
\hline TOTAL & 36 & $\begin{array}{r}100 \\
, 0\end{array}$ \\
\hline
\end{tabular}

* Em caso positivo: NOAM AD; LORIUM; LEXIL; EQUILID.

Em condições de ameaça, moderada ou intensa, as pessoas podem sentir a necessidade de procurar aju- da terapêutica e ou medicamentosa, enquanto outras sob provocação semelhante são capazes de tolerar altos niveis de tensão e ansiedade e portanto funcionar de maneira ajustada. No decurso do desenvolvimento normal, o ser humano aprende a defender-se contra o sentimento de ansiedade e a manter a sua integridade contra a ameaça externa.

\section{CONCLUSÕES E CONSIDERAÇÕES}

Conclui-se que a grande maioria dos sujeitos estudados:

6.1 Admitiu vivenciar a maior parte dos sintomas listados, considerando-os normais, sendo eles: ansiedade, desânimo, depressão, sentimento de inf erioridade, angristia, agressividade, vontade de agredir, insônia, agitação, apatia.

6.2 Evidenciaram-se, como sintomas não vivenciados e como anormais: alucinação, delírio, vontade de matar, idéias obsessivas, sentimento de perseguição, fobia.

6.3 Apresentaram dúvidas em enquadrar os sintomas: alucinação, delírio, fobia, depressão, etc., como normais ou anormais, deixando as lacunas em branco.

6.4 Enquadraram-se como indivíduo equilibrado, considerando-se como normais e dando ao conceito uma conotação de flexibilidade e relatividade.

Torna-se difícil afirmar a coerência da classificação quando o próprio indivíduo se classifica, na medida em que se constata a tendência a ser neste caso, mais condescendente e criterioso (uma coisa é rotular, outra é ser rotulado ou aceitar a rotulação). É importante que o que classifica o outro possa sentir, em si mesmo o ef eito e o incõmodo de ser classificado, e embora isto não apareça explicitamente, esta foi uma queixa freqüente por parte dos participantes.

Agradecimento ao auxiliar de pesquisa no levantamento dos dados: Adalberto J. C. da Rosa; Denize B. Munari; J. Francisco Filho; Leila A. Kauchakje; Luiz J. Pedrão e Renata C. Labate (alunos do curso de Pós-graduação - Área Enfermagem Psiquiátrica EERPUSP).

\section{REFERÊNCIAS BIBLIOGRÁFICAS}

1. BARRETO, D. O alienista, o louco e a lei. Rio de Janeiro, Petrópolis, Vozes, 1978. 139 p.

2. JACCARD, R. A loucura. Rio de Janeiro, Zahar, 1981. 117 p.

3. MAY, R. Psicologia e dilema humano. 3. ed. Rio de Janeiro, Zahar, 1977. 226 p.

4. Psicologia existencial. Porto Alegre, Globo, 1980

5. MILES, A. O doente mental na sociedade contemporânea. Rio de Janeiro, Zahar, 1982. 208 p.

6. PORTMANN, A. Brologishe Fragment Zueiner Lehre vom Menshcan. 2. ed. $258 p$.

7. SZASK, S. T. Ideologia e doença mental: ensaios sobre a desumanização psiquiátrica do homem. Rio de Janeiro, Zahar, 1977. $228 \mathrm{p}$.

8.. mito da doença mental. 2. ed. Rio de Janeiro, Zahar, 1979. 258 p. 